\title{
Baseball, History, the Local and the Global in Taiwan
}

\author{
Andrew D. Morris
}

\section{EDITORS' INTRODUCTION}

Baseball, like other sports, is entertainment. Also like other sports, it can be much more than that. Taiwan is a small place, yet its Little League teams became the most famous in the world. How can this possibly have happened? Clearly, baseball is something special in Taiwan. But baseball is an American game. Why would it become special in Taiwan?

In this chapter, Andrew Morris traces the particular case of baseball and shows how it has never been just entertainment for Taiwan. Taiwanese are fully aware of baseball's American and Japanese roots; it was introduced during the Japanese period. These associations make baseball cosmopolitan, international, and globally significant. The success of local teams in foreign fields takes on a cosmic significance as Taiwan shows itself internationally a force to be reckoned with. When its Little League players won international championship after international championship, Taiwan's position as a uniquely important world power simply could not be ignored, at least in this sphere. That was, of course, deeply satisfying.

Furthermore, since participation in amateur baseball is accessible to anyone with a bat and a ball-and since any school can afford the basic equipment for a small baseball team-players of talent can emerge anywhere. The internationally successful teams were drawn from counties and towns all up and down the island, filling baseball with the homey aura of heartland participation and the delicious possibility of rapid fame. A Taiwan baseball team was not just from Taibei or Tainan or liayi. It was pan-Taiwanese. 
The constant threats of conquest by mainland China over half a century have contributed to a growing sense of Taiwan being separate from China and of Taiwanese being different from Chinese. With the end of martial law, the assertion of independent Taiwanese identity has become far more open, and baseball, like other cultural expressions, reflects this. Baseball may even reflect the difference more than many other areas, because what stands out in Taiwanese baseball is not dependent on a broader Chinese heritage of its participants. It is not, after all, originally a Chinese game. To the extent that athletics involves Taiwan in an international arena, the identity of its teams and its people as Taiwanese in contrast to Chinese is thrown into particularly high relief.

From the beginning, baseball in Taiwan has had wider implications worthy of attention. In Taiwan, baseball was introduced as modernizing under the Japanese administration and evolved into a source of players for Japan's national teams. But as Taiwan's players gained the skills necessary to be taken seriously by Japanese teams, Morris argues, the clear implication was that in other ways, Taiwanese could also be the equal of Japanese, thus subverting the whole notion of Taiwanese subordination in Japan's colonial empire. Generalizing from this example, we may argue that obvious competence in a field as visible as competitive sports is inherently subversive of almost any outside attempt to classify a population as naturally or properly subordinate. Competitive sports, in other words, are inherently democratizing.

It is little wonder, then, that baseball has almost necessarily evolved in our era into a symbol of Taiwan's unique culture and its unique destiny.

On March 25, 2000, Chen Shui-bian (Chen Shuibian) chose a special engagement for his first public appearance as Taiwan's new president-elect. That night, Chen spoke at the Taiwan Major League's opening game, which also served as the opening ceremony of the new Chengqing Lake Stadium in Gaoxiong County. Before the contest between the Taizhong Robots and the GaoxiongPingdong Thunder Gods began, the capacity crowd heard the president-elect describe baseball as a "symbol of the Taiwanese spirit" in announcing that he would designate 2001 "Taiwan Baseball Year" and consider Gaoxiong County Magistrate Yu Zhengxian's proposal to designate baseball as Taiwan's national sport. In his customary self-deprecating fashion, Chen confessed to a childhood fascination with baseball and joked that he decided to be president only after he realized he was not athletic enough to succeed in baseball (TTO 2000; HXXWW 2000). ${ }^{1}$

President Chen's official attention to the game marks only the latest chapter in the history of Taiwanese baseball, a culture that has become much more than just a sport. It is a colonial legacy that was planted and sunk deep roots during the fifty-year Japanese occupation of the island from I895 to r945. The professional version of the game in Taiwan today is experienced as a reminder of the 
profound influence of American and Japanese culture-and indeed of transnational capitalism in Taiwan at the turn of the century. At the same time that these foreign legacies are crucial to the creation of Taiwanese cultural artifacts like baseball, other "Chinese" factors make the picture even more complicated. More than four decades of living under an authoritarian Chinese Nationalist (Guomindang) regime-combined with the feelings of fear and isolation produced by the blustery nationalism now emanating from the People's Republic of China (PRC)-have also led Taiwanese to fervently and enthusiastically celebrate their uniqueness, linguistic and otherwise, vis-à-vis the "Chinese mainland."

The combination of these interrelated legacies has thus given rise to the remarkable and striking quality of contemporary Taiwanese culture-namely, its strong dual emphases on and blending of the global and the local. Professional baseball in Taiwan is a perfect instance of this self-conscious, ideological combination of the global and the local, the cosmopolitan and the provincial, the international and the Taiwanese. The short history of professional baseball in Taiwan is in many ways nothing more or less than the history of the effort to create a "baseball culture" that could speak to both of these striking and complementary aspects of Taiwanese life.

The conditions outlined above make Taiwanese professional baseball unique in the sporting world. Models of colonial sport, such as that portrayed in the film Trobriand Cricket, where natives of the Trobriand Islands of Papua New Guinea transform cricket into a magical, mocking send-up of the colonial game (Leach r975), are clearly not useful in analyzing contemporary Taiwanese sport. Since World War II, the global relevance of modern sport and the emphasis on international adherence to these models has made it impractical or even impossible to imagine wholesale Taiwanese transformations of baseball, ${ }^{2}$ In fact, the application of any standard model of colonialism simply fails to capture the complexity of Taiwan's recent history under the hegemony of Japanese, Chinese Nationalist, and American colonial and military regimes. Instead, this chapter examines the conscious construction of Taiwanese professional bascball as an avenue that leads both to globalization and international acceptance, as well as to a local and unique Taiwanese identity.

\section{BASEBALL IN THE JAPANESE COLONIAL ERA}

Baseball in Taiwan, introduced by the Japanese colonial regime, has never thoroughly shed its Japanese heritage. From the name of the game, still called by many in Taiwanese $y a g y u$ (from the Japanese $y a k y \bar{u}$ and not the Mandarin bangqiu), to the Taiwanese-Japanese-English playground calls of "stu-rii-ku" and "out-tow," baseball's Japanese "origins" are still an important part of Taiwanese heritage. The sport, well developed in Japanese schools by the I89os (Roden I980, 520-529), was imported to the colony of Taiwan around I897, just two years after its incorporation into the Japanese Empire (Cai $\left.1992, \mathrm{r}_{3}\right) .^{3}$ Initially played by colonial bureaucrats, bankers, and their sons in Taihoku (Taibei), 
baseball spread to southern Taiwan by I9I0. In 19I5, the colonial government formed the Taiwan Baseball Federation, made up of fifteen (all-Japanese) school teams playing the quickly growing sport (Gao I994, 45; Zhan I985, 435).

It was not long before Taiwanese youth joined in this new fun. Around Igro, Taiwan Governor-General Sakuma Samata encouraged the development of the sport among Taiwanese youth. As he explained it, this was his humble way of repaying the local Taiwanese deity Mazu, who in I906 had appeared to his ailing wife in a dream and miraculously cured her (Gao I994, 4I). In I92I, a Hualian native named Lin Guixing formed the Takasago Baseball Team of Ami aborigine boys. Two years later the team changed its name to the High-Ability (Nōkō) Baseball Team when they all enrolled in the Hualian Harbor Agricultural Study Institute. Lin and his Nōkõ team achieved great fame when they traveled to Japan in the summer of I925 and won five of six games against Japanese school teams there.

The most famous of all Taiwanese baseball traditions was that born at the Tainan District Jiayi Agriculture and Forestry Institute (abbreviated Kanō) in the late I920s. Under the guidance of Manager Kondō Hyōtarō, a former standout player who had toured the United States with his high school team, Kanō dominated Taiwan baseball in the decade before the Pacific War. What made the Kanō team special was its tri-ethnic composition: In I93I, its starting nine comprised two Han Taiwanese, four Taiwan aborigines, and three Japanese players (Su I996, Io; Zheng I993, IO9-II5) . ${ }^{4}$ Kanō won the Taiwan championship, earning the right to play in the hallowed Kōshien High School Baseball Tournament held at Nishinomiya near Osaka four times between I93r and 1936. The best of these, the I93I squad, was the first team ever to qualify for Kōshien with Taiwanese (aboriginal or Han) players on its roster. ${ }^{5}$ Kano placed second in the twenty-three-team tournament that year, their skills and intensity winning the hearts of the Japanese public. ${ }^{6}$ Amazingly, this I93I Kano team is still a very popular nostalgic symbol even today in Japan (Su 1996, 40). This team of Han, aboriginal, and Japanese players supposedly "proved" to nationally minded Japanese, in an extremely visible fashion, the colonial myth of "assimilation" (döka) - that both Han and aboriginal Taiwanese were willing and able to take part alongside Japanese in the cultural rituals of the Japanese state. Of course, the irony is that the six Taiwanese players on the starting roster probably also saw their victories as a statement of Taiwanese (Han or aborigine) will and skill that could no longer be dismissed by the Japanese colonizing power. But the fact that this Kano triumph could be understood in such different ways is merely proof of the important and liminal position that baseball held in the Japanese colonial administration of Taiwan.

The great Kanö tradition was not Jiayi's only contribution to the Japanese baseball world; this southern town cemented its reputation as the baseball capital of Taiwan when several of its sons went on to star in baseball in Japan in the r930s and beyond. The greatest of these was Wu Bo, who starred on Kanō's 1935 and 1936 championship teams, signed with the proud Tokyo Giants baseball team in 1937, and played for the Giants for seven years. In 1943, under the nation- 
alistic pressures of wartime, Wu took the Japanese name Kure Masayuki (keeping the same surname, which is pronounced "Kure" in Japanese). The next year, however, he gave the Japanese baseball community a less polite reminder of his ethnic Chinese identity when he refused to travel to Manchuria with the Giants to arouse Japanese troops stationed there. Wu left the Giants outright, went on to play for another thirteen years with the Hanshin Tigers and Mainichi Orions, and in 1995 became the first Taiwanese player selected to the Japanese Baseball Hall of Fame (Gao r994, 94-95; Su 1996, 28). ${ }^{7}$

Taiwan did not just produce an elite class of standout baseball players. Baseball became popular at all levels, making it the dominant sport in the colony as it was in the home islands of Japan. Peng Ming-min would later trade his baseball mitt for a pen, enduring much sacrifice as he led the struggle for Taiwanese selfdetermination and independence during the Chinese Nationalist era. But as a boy in Japanese Gaoxiong during the I93os, young Peng was the typical Taiwanese schoolboy obsessed with baseball. In a conversation with me in I999, Peng fondly remembered huddling around the radio with his brother to listen to colonial broadcasts of the Japanese high school championships at Kōshien every spring. As Peng notes in his memoir, A Taste of Freedom:

By this time I was an ardent baseball fan. When Babe Ruth visited Japan I boldly wrote a letter to him and in return received his autograph, which became my treasure. . . . [I] reserved my greatest enthusiasm for baseball. Our school masters took baseball very seriously, treating it almost as if it were a military training program. Although I was a poor batter, I was an excellent fielder, and played on our team when it won a citywide championship. Needless to say, my Babe Ruth autograph gave me great prestige among my classmates. (Peng 1972, 16-I7)

The enthusiasm of millions of young people like Peng, who played and paid feverish attention to this Japanese institution, is what made baseball Taiwan's "national game" some seventy years before Chen's presidential remarks in 2000.

This Taiwanese excellence in baseball, the sport of the colonizing power, reflects an important aspect of the experience of almost any colonized people. Edward Said has discussed the "collaborative" aspect of the life of colonized intellectuals, whose long-term strategies for liberation depended on being able to "learn the ways of the [colonizer], translate his works, pick up his habits" (Said I993, 262). C. L. R. James has extended this model to the sporting world in his discussions of West Indies cricket, where by the early Igoos, the inspired performances of standout black cricketers forced white populations to give West Indians a respect they would not have granted otherwise (James I986, II8-124).

In Taiwan, baseball likewise was one way in which the colonized population sought to negotiate their relationship with the Japanese colonizing power on terms that the Japanese could not help but accept. There are more explicitly political analogues of this process in colonial Taiwan. One was the Home Rule 
Movement, under which Taiwanese students educated in Tokyo-citing the official rhetoric of authoritarian "imperial benevolence"-sought a colonial assembly for Taiwan in the early I920 (Kerr 1974, II3-I29). Taiwan elites' calls in the r.930s for Taiwanese to be allowed to serve in the Japanese military (as more than two hundred thousand Taiwanese later did during World War II) were also explicitly tied to appeals for equal treatment of the Taiwanese as subjects of the emperor (Kondö 1996, 34-36; Lin 1996, 217-227). Baseball was another such liminal realm where Japanese exclusion of Taiwanese baseball teams or players would have given the lie to Japan's entire colonial enterprise.

Baseball allowed the colonized Taiwanese, as Said has written of "native intellectuals" in other settings, to work within the constraints of the system in order to "liberate their energies from the oppressing cultural matrix that produced them" (Said 1993, 269). Indeed, this physical realm of baseball was one fraught with many tensions and contradictions; participation in Japan's "national game" allowed Taiwanese people to prove and live their acculturation into the colonial order at the very moment that Taiwanese baseball successes worked to subvert it. ${ }^{8}$ Taiwanese subjects, both Chinese and aborigine, could use baseball skills and customs taught by the Japanese to appeal for equal treatment within the national framework that baseball represented in so many ways. Yet the Taiwanese baseball community, through its many triumphs, was able to use this arena to offer the final proof, in a "national" language that the Japanese had to understand, that the colonial enterprise that aimed to shackle the Taiwanese population in permanent subservience was bound to fail.

\section{BASEBALL IN GUOMINDANG TAIWAN, 1945-1980S}

When the Guomindang state took the reins of Taiwan's government in late I945, it set out to effect two related transformations of the Taiwan polity. To truly achieve a Chinese "Retrocession" (Guangfu) of Taiwan, the Nationalists would have to strip Taiwanese culture of its Japanese legacies, while at the same time restoring to it an essential and timeless "Chineseness" for which the Taiwanese people presumably had been longing for a half century. Policies of "deTaiwanization" were enforced, officially degrading any distinctively Taiwanese cultures or customs. These policies were designed not only to cut the colonial links to Japan, but also to nip in the bud any heretical links between a culturally distinctive and politically separate Taiwan (Chang I993, I42-I45). These policies were even applied to the baseball realm as well; the Japanese stigma that the game carried in the late $x 940$ s was so potent that it was rare to find a Guomindang-fearing school administrator willing to accept the presence of a baseball team on his campus (Su I996, 27).

At the same time, however, state agents involved in Retrocession efforts also realized what a valuable exception baseball could be to this rule of erasing any and all colonial remnants. The Guomindang state had promoted physical 
culture in planning the construction of a strong and healthy Chinese populace and state on the mainland for two decades. Official endorsement of baseball soon became one method of officially "sinicizing" a cultural realm that still represented a Pandora's box of colonial thinking and customs. Baseball was included at the First Taiwan Provincial Games, held in October 1946 at National Taiwan University, with twenty counties, cities, colleges, and government organizations sending baseball teams to this meet overseen by Chiang Kai-shek (Jiang Jieshi) and Song Meiling, in Taiwan for the first anniversary of Retrocession (Taiwan sheng 1946,7, I5-52, 82-84; Su 1996, 27).?

A baseball tournament was held in Taiwan in August I947, even as government "anticommunist" forces continued their massacres, begun that March, of thousands of Taiwanese elites seen as a threat to Chiang's regime. It is telling that the baseball world was not able to escape this horror. Lin Guixing, coach of the great Hualian Nôkō teams of the 1920s, was killed on August I, I947, during the violent and sustained aftermath of the 228 Incident (Gao I994, 47-50), Fudan University and Shanghai Pandas teams also came to play against teams from Taibei, Taizhong, Taiwan Power, Taiwan Sugar, and Taiwan Charcoal, as if all was well that bloody summer (3I). In I949, a Taiwan Province Baseball Committee was formed, chaired by future ROC vice president Xie Dongmin, organizing annual provincial basebail tournaments at all levels of play (Zhan I985, 436).

What is interesting about these Guomindang efforts to promote baseball in Taiwan in the immediate postwar period is that Taiwan was clearly the only region of the Republic of China with any baseball tradition whatsoever. When the Taiwan Province Baseball Team won the championship at China's Seventh National Games in Shanghai in I948, there were only three other teams entered: the national Police and Air Force teams, both of which were stacked with Taiwanese players, and the lilipino Overseas Chinese team (Di qi jie I948, 30). In other words, the Guomindang could hardly promote baseball as a "Chinese" custom. Thus their work to hijack the game's unique popularity in Taiwan for their own uses still had to be in explicitly Taiwanese terms. The game of basketball soon became fashionable in Taiwan, promoted by the sizable waisheng mainlander population concentrated in the north. But baseball remained an arena in which Taiwanese people could successfully-and without any fear of reprisal-challenge the Guomindang's policies of "de-Taiwanization" and their claims to represent a true Chinese culture that Taiwanese needed for their own good.

Baseball, then, is also central to the story of Taiwan's rapid and traumatic transition from wartime to decolonization to a new oppression delivered in the rhetoric of Retrocession to Chinese rule. Said's model predicts decolonized intellectuals' work for the "rediscovery and repatriation of what had been suppressed in the natives' past by the processes of imperialism" (Said I993, 2ro). But in Taiwan after February 28, 1947, this process was unthinkable. At this moment, original support for Chinese rule of Taiwan had been dashed violently and unmercifully by the actions of tens of thousands of carpetbagging Guo- 
mindang troops, bureaucrats, and hangers-on. The relieved and enthusiastic searching for a "Chinese" Taiwan among Taiwanese thus quickly gave way to a yearning for cultural artifacts from the good old colonial days. Baseball was one of these artifacts, and this complicated picture of a Taiwan stuck between a Japanese rock and a Guomindang hard place explains much of baseball's continued popularity after the Japanese were long gone from Taiwan.

Yet the vagaries of decolonization and Retrocession do not provide the full extent of this history. The Taiwanese people now had to contend with the reality of an invigorated American Cold War imperialism that sought to dictate affairs in Taiwan and throughout Asia as a whole. Taiwan's baseball history offers a look at this process as well. In I95I, the first ever All-Taiwan baseball team was organized for a series of games versus Filipino teams in Manila. The Manila sporting public fell in love with the All-Taiwanese, especially the astounding home run hitting of Penghu native Hong Taishan. But the young team from Taiwan made an even deeper impression when they "volunteered" to give blood to American soldiers recuperating in Manila hospitals from casualties sustained in the Korean War (Gao 1994, I3-I6). This episode, though anecdotal, thus provided a most profound metaphor to describe life in small Asian nations during the depths of the Cold War. In the end, the greatest triumphs that could be won were in activities (like baseball) defined and approved by the United States, in locales dependent on and exposed to American beneficence and greed, and in ways that figuratively sucked life from these locales as they were integrated into America's new postwar empire.

This incredible tightrope walk between Japanese colonialist legacies and Guomindang-U.S. hegemony in Taiwan continued into and was in many ways exemplified by the international success of Taiwanese Little League baseball (Shaonian bangqiu, or Shaobang) teams beginning in the late ro6os. In a tremendous run perhaps unmatched in the history of international sport, Taiwanese teams won ten Little League World Series titles between 1969 and $198 \mathrm{I}^{10}$ and sixteen in the twenty-seven-year period from I969 to 1995. This success brought desperately needed attention to Taiwan in a time when its most important ally, the United States, was gradually shunning the island in favor of ties to the People's Republic of China. But it also allowed the playing out of a very complicated jumble of national and racial tensions that make a study of Taiwanese baseball crucial to a deeper understanding of Taiwanese society during this era.

This Little League success began in August 1968 with two great victories by the Maple Leaf (Hongye) Elementary School team over a visiting team from Wakayarma, Japan. This Hongye Village team-made up of Bunun aborigine youth representing their tiny Tajdong County school of just a hundred students-earned the right to play Wakayama after winning the islandwide Students' Cup tournament held in Taibei. They then became superstars after their victories over Wakayama at the Taibei Municipal Stadium. The twenty thousand fans who managed to get tickets for each of these historic games were joined by an islandwide television audience treated to more than thirteen hours of Taiwan 
Television broadcasts on the first game alone (Wang 1994, 66-74). The overall significance in Taiwan of the Maple Leaf boys' success is hard to measure. Virtually all of Taiwanese society was energized in a way that has few parallels in American history-the Olympic triumphs of Jesse Owens or the 1980 hockey team being perhaps the closest examples. To this day, the Maple Leaf's Ig68 victories against Wakayama are cited as a defining moment in the history of Taiwanese nationalism. In fact, a print advertisement for a set of two books chronicling twentiethcentury Chinese history, published in Taiwan in 2000, featured five photographs of the crucial moments of this century: the IgIr revolution, the I945 surrender of Japan after World War II, the Great Leap Forward famine of the early I960s, Taiwan's withdrawal from the United Nations in 1971, and the Maple Leaf baseball triumphs of 1968 (Changrong 2000,85 )!

Unfortunately, the jubilation at these victories was soon dampened by an unfortunate revelation. On their roster of eleven players, the Maple Leaf team included nine ineligible boys who were playing under false names (Wang r994, $5-6) .{ }^{11}$ Nonetheless, these great victories by aboriginal village youths from Taidong County constituted a tremendous moment in modern Taiwanese sports and cultural history and announced to the world that Taiwan was ready to join -in this realm of competition at least-the powers of world sport.

The next year, 1969, was Taiwan's first entry into the Little League World Series, operated by the U.S. Little League establishment and held in Williamsport, Pennsylvania. The youth of Taiwan spared no time in making this tournament a yearly blowout of any and all challengers. The Taizhong Golden Dragons, Taiwan's I969 champions, "surprised everyone from Japan to the U.S." as the Sporting News put it, sweeping opponents from Ontario, Ohio, and California to take the world title. An impressed-if politically incorrect-Sporting News described the skill and infectious enthusiasm of "the Orientals":

Thousands of gong-clanging, cheering fans in the stands at Williamsport adopted the Chinese as their favorite team.

[Chen Zhiyuan] captured the fans' imagination when, after every out, he'd turn around and shout to his fielders, raising the ball above his head. In return they yell in Chinese the American equivalent of, "Go men!" (Keyes 1969)

Guo Yuanzhi-one of the stars of this team who went on to become a legend in Japan, pitching for the Chunichi Dragons for sixteen years-later remembered his teammates' racial jitters at being the only "yellow" players in Williamsport. They overcame these fears by using the taller physiques of their Western opponents against them, throwing them numerous curve balls that they felt the longer-armed North Americans would have more trouble hitting (Guo 1998, 45). Their confidence was also boosted by the presence at their games of thousands of delirious Taiwanese and Chinese flag-waving fans-residents of the United States who would make these yearly baseball pilgrimages to Williamsport for decades to come. 
Fans at home in Taiwan were even more jubilant, glued to their radios into the wee hours of that humid summer night. One radio DJ remembered thirty years later how "the Taipei night nearly boiled over. When the game finished at 3 A.M., the streets of the city erupted with the constant banging of firecrackers, as ordinary citizens opened their windows and yelled out to the night sky, 'Long live the Republic of China!'" (Li I999, Ior). At a time when Taiwan's standing in the international community was becoming less and less stable, this, like the Maple Leaf triumphs the year before, was a satisfying victory indeed.

Yet this championship, unfortunately, was also plagued by irregularities. It was common knowledge in Taiwan that the I969 world champions-technically a school team from Taizhong in central Taiwan-had actually been recruited as a national all-star team (guojia daibiaodui), a fact that clearly violated the Williamsport charter. Only two of the team's fourteen players actually came from Taizhong! Nine of the starting players were from Jiayi and Tainan in the south of the island. Star Yu Hongkai, from Taidong, had played illegally as a ringer for the I 68 Maple Leaf team and was recruited from across the island for the rg69 Golden Dragons. Guo Yuanzhi, the future Japanese pro star, was also recruited from far Taidong for the World Series (Su 1996, 43; Wang 1994, 48).

This trend would not end soon. The r970 "Jiayi Seven Tigers," the only Taiwan team not to win at Williamsport over the next decade, included only seven Jiayi boys, supplemented by five Tainan and two Gaoxiong players. As late as I979, the Puzi Elementary School Tornadoes world championship team included two ringers from elsewhere in Jiayi County (Su 1996, 55, 7I). These teams-and rightfully so-generated great suspicion on the part of an American public unable to fathom the source of this invincible Taiwan baseball dynasty. In fact, by the end of this run, the phrase "Taiwanese Little League baseball," like "Texas high school football" or "East German women's swimming," became a standard metaphor for those who would use youth sports to achieve victory with no regard for the rules of "fair competition."

Yet this view of their Little League program mattered little to the Taiwanese public of the time. In 197I, when the Tainan Giants won the Williamsport championship, some ro million people in Taiwan-an incredible two-thirds of the island's population-watched the game on television from 2:00 to 5:00 A.M. (Appleton 1972, 37). Baseball stardom became an almost universal aspiration among the boys and young men of Taiwan. Li Kunzhe, who starred professionally for the China Trust Whales in the late I9gos, remembers: "I grew up watching baseball. ... I remember the days when everyone would wake up in the middle of the night to watch our national teams perform in the international competitions. They were national heroes. We all wanted to represent our country and be a hero" (Li 2000, 8).

These triumphs were especially thrilling for Taiwanese people given the island's unique geopolitical squeeze described above. The sight of these Taiwanese boys annually making mincemeat of the strong and confident Ameri- 
can teams was pure bliss to anyone hoping to strike back and prove the strength and general worth of Taiwan to their American "allies" so busy selling out Taiwan in favor of relations with the PRC during the I97os. Indeed, the humbled Americans were reduced to booing these Taiwanese youngsters (when the Tainan Giants won again in 1973, as it happens, on their third consecutive nohitter) and eventually even banning all foreign teams for a year in I975 in order to guarantee an American "winner" (NYT August 26, I973, V-5; NYT November I2, I $974, \mathrm{I}, 5 \mathrm{I}$ ).

Most importantly, success in this Taiwanese (and not mainland Chinese) sport of baseball invigorated dissidents and critics of the Chiang Kai-shek regime thirsting for tangible measures of uniquely Taiwanese accomplishment. Williamsport soon became a "new battlefield" for Taiwanese dissidents and independence activists (Taiwan duli 2000, 58). In 1969, frenzied Taiwanese fans shouted upon the Golden Dragons' victory, "The players are all Taiwanese! Taiwan has stood up!" (Guo I998, 48). Taiwanese supporters soon raised the stakes in this implicit protest against the Guomindang government. In I97I, as the Tainan Giants swept to a world championship, Taiwanese Independence activists at Williamsport hired an airplane to fly over the stadium towing a bilingual banner reading, "Long Live Taiwan Independence [Taiwan duli wansui], Go Go Taiwan" (Taiwan duli 2000, 58). ${ }^{12}$ The Taiwan teams' games attracted fans from all points of the political spectrum, so each Taiwan Independence flag or banner was matched by pro-Nationalist mainlander fans waving national flags and cheering for the "Chinese" team. The pro-state fans had an advantage, however, in the dozens of New York Chinatown thugs hired by the Guomindang to identify and rough up Taiwan Independence activists at the games. That same year of 1971 , the championship game was interrupted when a dozen of these toughs ran across the field to rip down a banner reading in English and Chinese, "Team of Taiwan, Go Taiwan [jiayou Taiwandui]" (Taiwan duli 2000, 58; Taipingshan $1971,54-55)$.

In 1972, when the Taibei Braves challenged for the world title, the Guomindang was better prepared, renting every single commercial aircraft for miles around to keep the Taiwan Independence crowd from repeating their coup (Taiwan duli 2000,58). Some seventy to eighty military cadets training in the United States were also recruited to Williamsport, where they shouted while beating Taiwanese male and female supporters with wooden clubs, "Kill the traitors [Shasi hanjian]!" (Yi wei I972, 45-46). One wonders what American fans at Williamsport thought of all this violence, but these concerns did not stop either side from carrying out their battles. In 1973 at the Senior Little League Championships in Gary, Indiana, four activists wore T-shirts reading Tai, Du, Wan, and Sui (Long Live Taiwan Independence), only to have Guomindang officials in attendance order that they be arrested by Gary police as terrorists (Taiwan duli 2000, 59). At Gary in I975, Taiwanese activists floated a balloon with this same independence message, and thanks to the generous and curious $A B C$ cameramen on the scene, this sky-high subversion flashed across millions of 
Taiwanese television screens for the first time in history. ${ }^{13}$ Thus, through the manipulation of satellite technology and the tweaking of the connection between sports and nationalism that the Guomindang itself had tried to disseminate in Taiwan, Little League baseball became one of the most effective and joyous ways of challenging Chinese Nationalist hegemony in Taiwan.

Finally, the world of baseball was an important site for the expression of strength and pride among Taiwan's aboriginal tribes. Many of Taiwan's early championship teams were from the aboriginal areas of eastern Taiwan. These youngsters and their adult followers could only have taken an ironic pleasure in winning such great honors for-and being feted by-the oppressive Guomindang state that only continued to ignore and impoverish these representatives of a pre-Chinese Taiwan past. In fact, their baseball and sporting success in general became one of the most important ways in which Taiwan's aboriginal citizens represented and understood their identity and position in Taiwan society (GuO I998, 26; TTO May 28, 2000).

Yet clearly, this gratifying annual attention paid to the original inhabitants of Taiwan and their baseball prowess was not enough to truly sustain the aboriginal populations. It is telling that Taiwan's two greatest exports to Japanese basebail-Guo Yuanzhi (Kaku Genji) and Guo Taiyuan (Kaku Taigen)--were both Little League icons of aboriginal descent. Both Guos left Taiwan as very young men, settled and married in Japan, and only returned to the Taiwan baseball world in the late Iggos after their careers in Japan came to a close. ${ }^{14}$

The many jumbled and precarious directions along which Taiwanese baseball developed in the first four decades of Guomindang rule did not resemble in the least the neat white straightness of the baseball diamonds that were home to this movement. In the martial law days of mainlander domination of the Guomindang Party and state, baseball was one realm in which Taiwanese people could register their own contributions to Taiwan culture and society. This mixture of mild pro-Japanese nostalgia, ${ }^{15}$ resistance against Guomindang hegemony in Taiwan and American hegemony in East Asia, and even aboriginal resistance to the double oppression of the mainlander and Taiwanese Han presence could all be voiced in the language of baseball. But what made this dissent safe was the Guomindang's own understanding of the role of sports in modern society. Their standard two-part philosoply, developed when the party ruled China in the late I920s and I930s, was that popular participation in sports served to integrate a diverse population into a single nation-state and that outstanding sporting performances on international stages were valuable opportunities to win national face, sympathy, and even allies in the ever-changing world of the twentieth century. ${ }^{16}$ Thus, in many ways baseball represented a table of negotiation in which Taiwanese baseball communities exchanged measures of integration for measures of independent expression, measures of "Chinese" identity for measures of pro-Japanese nostalgia, and measures of the autocratic martial law Guomindang state for measures of an independent Taiwanese culture and society. 


\section{CHINESE PROFESSIONAL BASEBALL LEAGUE: BEGINNINGS, 1990-1994}

Planning for a Taiwanese professional baseball league began in late 1987 , the year that martial law was lifted in Taiwan (Zeng I997, 22). The events of this year marked the end of four decades of naked authoritarian rule by the Guomindang and signaled the beginning of a new era in Taiwan, where there was now space to redefine identities and historical memories once drawn along the lines of Japanese, Chinese, and American hegemony. By this time, two different movements had emerged in this new Taiwan. The first was to define a unique identity for the Chinese-but-not-really-Chinese island nation. This "uniqueness" in turn would aid in the second-the scramble to ensure Taiwan's inclusion in a new globalizing world order. Both of these impulses, along with the entrepreneurial drive perfected in I980s Taiwan, came together perfectly with the I988 public announcement that the Chinese Professional Baseball League (CPBL, or Zhonghua Zhiye Bangqiu Lianmeng) would begin play in I990. ${ }^{17}$

The new CPBL consisted of four corporate-owned teams: the Weichuan Dragons, Brother Elephants, President Lions, and Mercuries Tigers. ${ }^{18}$ These teams' uniforms clearly demonstrated the CPBL's efforts to present a product that was a pleasurable mix of the global and the Chinese: The teams' names and parent companies were represented on the jerseys and caps in various mixtures of English and Chinese lettering. The four corporate-owned teams did not represent cities, as teams do in most professional leagues; instead, the teams toured up and down the island's west coast together, playing weekly round-robin series in Taibei, Taizhong, and Gaoxiong. Each of these cities (plus Tainan, Xinzhu, and Pingdong, where a few games were scheduled every year) had their own fan clubs organized to support each of the CPBL's four teams. The majority of these fan club members were male high school or university students, but these fan clubs were also filled with significant numbers of female students, businessmen, and laborers (Shih $\mathrm{r} 998,37-39,80$ ). The enthusiastic rooting of these fan clubs (houpuanhui, from the Japanese köenkai) could at times very easily turn violent. The sight of angry fans-Lions fans in the President Corporation's hometown of Tainan were particularly famed for this-hurling bottles, cans, eggs, and garbage at opposing players or even surrounding the opposing team's bus in a mob was not uncommon in the league's early years, giving the lie to the notion of a united Taiwan cheering on a united CPBL.

Another important element of the new Chinese Professional Baseball League was the presence of foreign players (usually called yangjiang, or "foreign talents") culled from the rosters of American Double-A minor-league teams. ${ }^{19}$ Twenty-three players, American and Latin American in origin, went to Taiwan in the winter of 1989 -1990 for tryouts. Sixteen were selected to join the CPBL (with a league limit of four yangjiang per team). The presence of these players was meant to add an international flavor to the league and also to provide an external stimulus for the improvement of the quality of CPBL play. In a 1993 
conversation, Jungo Bears pitcher Tony Metoyer described to me how these foreign players also served as "silent coaches" who could share their knowledge of American strategies and training methods with the Taiwanese players. Their many contributions allowed the Taiwanese game to become closer in strategy to the more open or risky style of baseball played in the Americas and less like the conservative game that suited Taiwan so well in its years of Little League dominance.

Steps were also taken to sinicize the identities of these foreign players as well. Each of the players was given a "Chinese name," usually sounding something (if only vaguely) like the player's original name, and one which usually bestowed fine and admirable qualities on the foreigner. Elvin Rivera, a Dominican pitcher selected by the Tigers, became "Li Wei" - "Li" as the common Chinese surname and "Wei" meaning "great" or "mighty." Freddy Tiburcio, the Elephants' star Dominican outfielder, was called "Dibo," or "imperial waves and billows." Luis Iglesias, the Tigers' home run champion from Panama, was called "Yingxia," or "chivalrous eagle." These players were photographed for magazine covers dressed in "traditional" Chinese scholars' caps and robes, as Taiwan's baseball public was taught that even in the realm of baseball, a game having explicitly foreign origins, the Chinese ability to assimilate outsiders was as powerful as ever.

Yet this "assimilation" could occur on the most materialistic terms, as many of the foreign players' "Chinese" names were just advertisements for products sold by their team's parent corporation. The Mercuries Tigers inflicted names of noodle dishes (Qiaofu, Quanjiafu) from their chain restaurants onto pitchers Cesar Mejia and Rafael Valdez. The President Lions, whose parent company specialized in convenience stores and prepackaged foods, did the same with the names Shengmaige (San Miguel beer), A-Q (instant noodles), and Baiwei (Budweiser) for pitchers Aguedo Vasquez, Jose Cano, and Ravelo Manzanillo. Later, the China Times Eagles resourcefully used names from their minor corporate sponsors, dubbing pitcher Steve Stoole "Meile" (Miller Beer), calling the Afro-Dominican outfielder Jose Gonzalez "Meilehei" (Miller Dark!), and former New York Mets infielder Brian Giles "Aikuai" (Alfa Romeo). Practices like this served to maintain some distance between the Taiwanese and these foreigners, assimilated or not.

Real outsiders from the larger world of baseball came to Taiwan to endorse the CPBL enterprise as well, as the league in its early years won several valuable publicity coups. The Chunichi Dragons ${ }^{20}$ and San Diego Padres sent minorleague teams to Taiwan for exhibition series against CPBL teams after the I99I. and 1992 seasons. Then in I993, the Los Angeles Dodgers major-league squad visited, only to be beaten in two of three games by Taiwan's CPBL teams! The presence in Taiwan's ballparks of these representatives of the great American and Japanese baseball traditions only boosted the status of the CPBL in the eyes of Taiwanese and foreign baseball communities.

Besides this conscious effort to connect Taiwanese baseball and culture to the greater international baseball and cultural worlds, efforts were also made to emphasize the CPBL's local composition in marketing the league. The most di- 


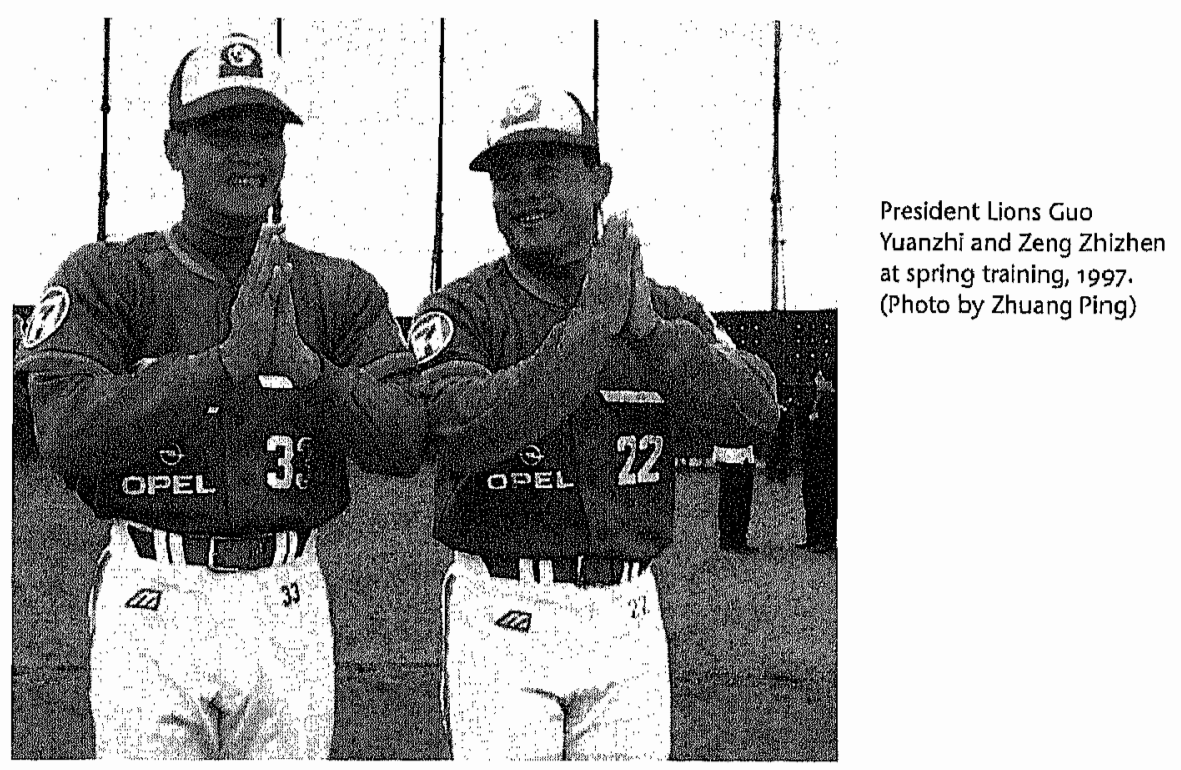

rect connection was the presence of former Little League heroes who had won such great honors for Taiwan in the r970s. During their prime years in the I980s, before the Chinese Professional Baseball League was founded, these heroes could play only in Japanese or Taiwanese semipro leagues. The CPBL was extremely fortunate to have begun play while this celebrated group still was in command of most of their skills; after a few years of play, it was obvious that the careers of some of these ex-child stars were heading south. But their presence in the CPBL's first years of play was crucial in making the league a viable enterprise.

Other accoutrements of "traditional Chinese culture" helped cement the league's special Chinese characteristics as well. Fan favorites like Dragon pitcher Huang Pingyang and Lions captain Zeng Zhizhen (known as "The Ninja Catcher") were often featured in magazines that told of their pursuits of selfconsciously Chinese or Taiwanese customs, like drinking fine tea, taking in traditional Taiwanese puppet theater, or collecting teapots or Buddhist paintings. Popular television variety shows even featured noted numerologists and geomancers using these "traditional" Chinese sciences to predict the results of upcoming baseball seasons.

Thus the roots of the CPBL's early success lay in this important effort to combine the local and global. International symbols of sporting culture were carefully balanced with aspects of the local, expressed through the involvement of particular individuals identified with past Taiwanese sporting successes or through linguistic or cultural particulars that remained a part of CPBL baseball. This strategy, the key to the CPBL's successes in the early I990s, is strikingly different from the model by which Tokyo's Yomiuri Giants became such a powerful symbol of Japanese pride and strength during the late Ig6os and I970s. An- 
thropologist William Kelly has outlined the history of the Giants' nine-year run of consecutive championships won from 1965 to 1973 , a reign that "precisely mapped postwar Japan's double-digit boom years that catapulted the country to the first rank of industrial powers" (Kelly I998, I05). The Giants organization insisted on maintaining a "pure" Japanese team, refusing even to allow the great Japanese-Hawaiian star and three-time batting champion Wally Yonamine to remain a Giant. The Giant cult was constructed atop beliefs of "uniquely Japanese" elements of a "fighting spirit" (konjo) and strategies of "managed baseball" that mimicked new forms of corporate organization and became an important brick in the wall of an essentialist, culturally and racially defined postwar Japan (105-107).

Yet there is literally no analogue between the cult of the Yomiuri Giants and the rise of professional baseball in Taiwan. For an island that has always been as politically and ethnically complicated as Taiwan, this kind of national or racial chauvinism was impossible. There was tension, however, between notions of a uniquely "Taiwanese" identity emerging in I99os Taiwan and some of the essential "Chinese" gimmicks used to show how baseball was being assimilated into Taiwanese/Chinese culture. In the CPBL, explicit "Taiwan consciousness" took second stage to the exaggerated "Chineseness" of the league's image, and this crack in the CPBL's fun mixture of international and local cultures would be exploited by later competitors.

\section{MINOR-LEAGUE FOREIGNERS AND TENSIONS IN "CHINESE" BASEBALL}

The CPBL reached its peak popularity, measured by crowd attendance, in its third through fifth seasons, I992-I994 (see Table I). In 1993, the league was joined by two new teams-the Jungo Bears and the China Times Eagles-meach loaded with seven young, popular members of Taiwan's I992 silver medal Olympic baseball team. That same season, the all-sports station TVIS paid NT $\$ 90$ million (U.S. $\$ 3.6$ million) to broadcast CPBL games over the next three seasons-hardly American network money, but a great improvement over the NT $\$ 3,000$ (U.S. $\$ 120$ ) per-game fee paid by Taiwan's major broadcast stations up to that point (Chen r996, 80). CPBL games were being televised in thirty-eight different countries covered by Rupert Murdoch's STAR-TV enterprise (Wilson I993, 3). At the same time, the league also actively expanded its schedule into the Xinzhu, Tainan, and Pingdong markets, bringing quality baseball to the hometowns of more baseball-starved Taiwanese.

But somehow, despite all these signs of vigorous growth, the league's popularity began to wane seriously by 1995 , as the game began to lose the local Taiwan flavor it had worked so hard to cultivate. The CPBL mishandled the important balance between the local and the international that was so crucial in sustaining public interest in the league, as owners developed a dependence on international networks that made the league simply less appealing. 
Table 1 CPBL and TML average attendance, 1990-2002

\begin{tabular}{ccc}
\hline YEAR & $\begin{array}{c}\text { CPBL } \\
\text { ATTENDANCE }\end{array}$ & $\begin{array}{c}\text { TML } \\
\text { ATTENDANCE }\end{array}$ \\
\hline 1990 & 5,000 & - \\
1991 & 5,836 & - \\
1992 & 6,878 & - \\
1993 & 5,928 & - \\
1994 & 5,954 & - \\
1995 & 5,488 & - \\
1996 & 4,548 & - \\
1997 & 2,041 & 2,041 \\
1998 & 2,191 & 3,442 \\
1999 & 1,786 & 3,296 \\
2000 & 1,676 & 3,922 \\
2001 & 1,876 & N/A \\
2002 & 2,957 & N/A \\
\hline
\end{tabular}

Source: "Zhonghua" 2002; Naluwan 2000.

Perhaps the most visible form of this dependence was the CPBL's reliance on the foreign ballplayers invited to Taiwan to supplement the native rosters. Although most of these foreign players were AA-level minor leaguers who would never reach the American major leagues, several of them were able to excel in Taiwan. It became apparent in the league's first year that a team's success could depend heavily on the performance of their foreign "supplements." Teams began putting more emphasis on the foreign element of their roster, seeing it as the quickest path to improvement; it was certainly easier to wave money at a foreigner with proven skills than to dedicate several years to developing a Taiwanese player from scratch. The situation was exacerbated more when, in I994, the board of CPBL owners raised the foreign player maximum to seven per team. (By contrast, Japanese and Korean pro teams today are allowed to carry only four and two foreigners on their rosters, respectively.) In I995 this ceiling was raised to ten foreigners per team, and in March 1997, the league owners voted to eliminate all limits whatsoever on roster composition.

Public interest in the league fell consistently as the CPBL became less and less "Chinese" or Taiwanese and more and more reliant on American and Dominican players. By 1995, fully 44 percent of the CPBL's players came from outside Taiwan. Many of these yangjiang made the situation even worse. Some admitted far too candidly to being baseball mercenaries in Taiwan solely for the relatively high salaries they could demand there. Others alienated local residents and fans with their promiscuous and sometimes even brutish behavior; in fact, an entire book was published on the topic, entitled Foreign Pro Baseball Players' Sex Scandals (Gu r997).

In 1998 , commenting on the dominance of foreign pitchers in the CPBL, a Liberty Times columnist summoned up ugly images from modern Chinese his- 
Table 2 Number of foreigners and total players on all CPBL teams, 1990-2002

\begin{tabular}{cccc}
\hline YEAR & FOREIGN PLAYERS & TOTAL PLAYERS & AS \% OF TOTAL \\
\hline 1990 & 19 & 99 & 19.2 \\
1991 & 24 & 100 & 24.0 \\
1992 & 33 & 111 & 29.7 \\
1993 & 48 & 153 & 31.4 \\
1994 & 58 & 169 & 34.3 \\
1995 & 78 & 177 & 44.1 \\
1996 & 61 & 172 & 35.5 \\
1997 & 93 & 221 & 42.1 \\
1998 & 116 & 226 & 51.3 \\
1999 & $\mathrm{~N} / \mathrm{A}$ & $\mathrm{N} / \mathrm{A}$ & $\mathrm{N} / \mathrm{A}$ \\
2000 & 11 & 115 & 9.6 \\
2001 & 13 & 110 & 11.8 \\
2002 & 17 & 114 & 14.9 \\
\hline
\end{tabular}

tory in calling the league's pitching mound a "foreign concession" (waiguo zuiie). ${ }^{21}$ Indeed, the predominance of foreign pitchers that season reached ridiculous heights. Of the hundred CPBL pitchers who took the mound that year, only twenty-two were Taiwanese. The 1998 CPBL champion Weichuan Dragons carried twelve foreign pitchers on their roster (combined record 56 wins, 48 losses, and one tie) but only two Taiwanese pitchers (combined record o-0-o) ${ }^{22}$ Not only were a great percentage of the players foreign, but many teams preferred to hire foreign managers, thought to have a more worldly grasp of strategy than native Taiwanese managers. The success of Elephants Manager Yamane Toshida, who led his team to three straight championships from I992 to r994, made quite an impression on league owners searching for that extra edge. By 1995, five of six CPBL teams were managed by Japanese helmsmen.

The baseball community's mixed feelings about these foreigners who took over their league were manifested in many ways. Chen Dashun, a Dragon star first baseman turned columnist, reflected on the difficulty of creating a "local [bentu] baseball culture" in a league dominated by foreign players, and described Taiwan baseball culture as ultimately and frustratingly "not Chinese and not Western" (bu zhong bu xi) (Chen 2000, 19).

Popular baseball cartoons drawn by artist Ao Youxiang demonstrate aspects of this ambivalence in a much less sensitive way. Some cartoons show foreign players (particularly players of African descent) as simply big and dumb, unable to comprehend any but the most corporeal of sensations. In one, a black batsman (with absurdly exaggerated "Negroid" facial features) is hit in the groin by a pitch. As the batter rushes the mound, players of both teams follow, fearful of the damage to be done to the Taiwanese pitcher by this enraged black behemoth. But all are stunned when he arrives at the mound, evidently unfazed by pain that would fell any normal man, and thanks the pitcher for breaking up his kidney 


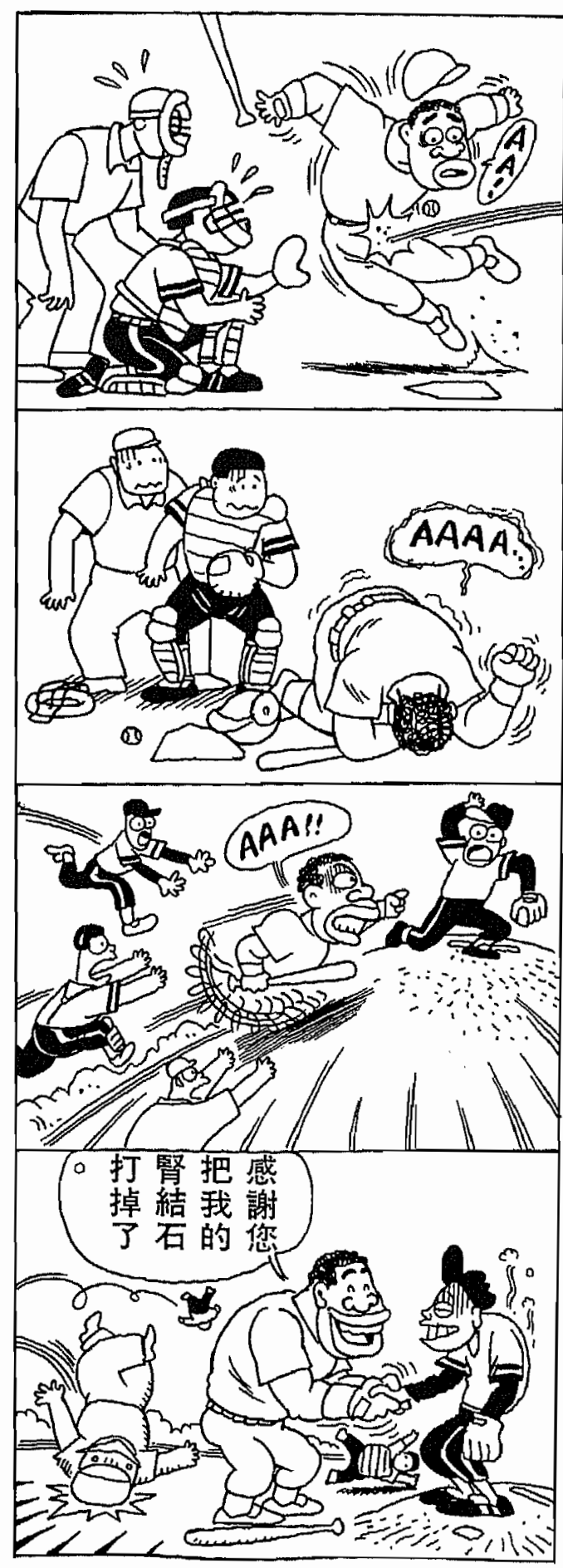

"How brave of you, to dare to

hit me!" (Cartoon by Ao

Youxiang, from Pro Baseball

Rhapsody, 1994: 28.) 
stones (Ao I994, 28). Another cartoon shows a black baserunner, styling himself as "the American stolen base king," vainly assured in his attempt to steal second base. But he is fended off by a wily Taiwanese shortstop, who sends the silly American scampering back to first base by waving a plate of "stinky tolu" his way (42). These stereotypes of the clever and rational Chinese versus the physically gifted but dimwitted black man were tired, ignorant, and tellingly provincial, but these cartoons did show the degree to which many felt betrayed by what was supposed to be Taiwan's own baseball league.

In an editorial written in March I997, a Taiwan sportswriter addressed in a different manner the problem of the dominance of foreign players in Taiwan baseball. He credited the yangjiang with aiding the development of pro baseball in Taiwan. But he reminded fans that the use of these foreigners truly came down to one question: Would these "AAA-level [minor-league] foreigners [laowai]" ever be able to help Taiwan win an Olympic medal in basebail (MSB March 9, 1997, 5)? In terms of national loyalty or the crucial international baseball stage, these foreign players could never truly contribute anything to Taiwan's future,

Fans' own wishes for a more Taiwan-centric CPBL could be seen in voting for the annual All-Star Game. In a I997 season marked by foreign dominance more than any other, ${ }^{23}$ fans did not select a single foreigner to the All-Star teams, picking marginal (at best) players like Whales outfielder He Xianfan (batting average ,2I8) and pitcher Huang Qingjing (I win and 9 losses, 5.65 ERA) to the teams over the dozens of foreign players who were more deserving by any statistical standard. From artists to columnists to fans themselves, the CPBL community began making explicit statements about the kind of local flavor they wished the league had retained since its more successful early years. The presence of these foreign players and managers achieved one of the original goals of this yangiiang strategy in that the quality of CPBL play improved greatly over the league's first liew years. Yet it is also telling that as the CPBL improved in technical terms, it simultaneously became a subject of such little interest to Taiwanese baseball fans.

Even the baseball clubs themselves seemed to mock the foreign players who had overtaken the CPBL game. In I998, after the practice had been prohibited for years, some teams resumed the awarding of outright, even crudely commercial Chinese names to foreign players. Al Osuna, who pitched for the Astros, Dodgers, and Padres in the American major leagues, was signed by the Mercuries Tigers that year and given the Chinese name Napoli-the same name as the local pizza restaurant that gave away a hundred free pizzas every night Osuna started a game (ZYSB May 28, I998, C-Io). The Sinon Bulls (formerly Jungo Bears), owned by the huge Sinon Agrochemical Corporation, in 1997 cleverly named several of its foreign players after the conglomerate's best-selling pesticides (ZYSB March II, r998, C-6)!

There were other ways in which an overdependence on international parties and networks hurt the CPBL in the eyes of its fans. The Sinon Bulls management has long-standing ties with Los Angeles Dodgers owner Peter O'Malley. 
Since I997, the Bulls have held their spring training camps at the famed Dodgers Baseball Academy at Campo Las Palmas in the Dominican Republic. In February I997, the Bulls announced that they and the Dodgers planned to cooperate in building a Professional Baseball Academy in Xiamen, China, based on the model of the Dodgers Dominican facility (TWRB February I7, I997, 9). ${ }^{24}$ This Dodgers influence, however, was viewed by many Taiwanese fans as more threatening than the all-American franchise would have liked. In May I997, when the Bulls decided to fire Korean manager Kim Yong Woon and his coaches, hiring outfielder Wang Junlang as player-manager, rumors flew through the CPBL that a group of Dodgers coaches soon would come to take over the team. In fact, Teddy Martinez, a coach in the L.A. system, did arrive soon after to serve as Manager Wang's "special assistant." Martinez stayed well within his defined "assistant" role, but this instance showed just how fragile the public imagined Taiwanese control of the team to be. If the imagined Dodgers takeover did not take place, it is still useful to see just how much power the Dodgers organization-one of the most fitting symbols of American paternalism and cultural hegemony-was imagined to have in this Taiwanese league on the other side of the Pacific Ocean. Indeed, this ominous view of the Dodgers proved to hold much truth when, in January r999, the team signed twenty-one-year-old Taiwanese superstar Chen Chin-feng (Chen Jinfeng) to a seven-year contract in clear violation of all Chinese Taipei (ROC) Amateur Baseball Association regulations (TWRB January 6 and 7, I999, B-7).

Having been established at an important turning point in modern Taiwanese history, when Taiwan's society, culture, and Taiwanese identity itself were being redrawn, the CPBL originally was able to capitalize on and define the trends of the times. It held great appeal for many in Taiwan, who sought both to explore and to learn more about the world that was now so much more accessible to them-and also to finally establish what it really meant to be "Taiwanese." The league's attempt to establish connections with international baseball and cultural networks while at the same time retaining a self-consciously local identity was a perfect strategy for the time. But after just five seasons, the league's popularity went into decline when this fine balance was lost by careless and short-sighted team owners entranced by the quick-fix talents of American and Dominican players. This overdependence on the foreign only served to make the CPBL seem a slave to the hegemonic forces of American sport that the league was supposed to mediate and resist in the first place and extinguished much of the enthusiasm so evident in the early I99os for this enterprise.

\section{THE TAIWAN MAJOR LEAGUE}

In December I995, a new chapter in the story of Taiwan baseball began. A group of investors, led by Qiu Fusheng and Chen Shengtian of the Era Communications and Sampo Electronics dynasties, announced the formation of a new Naluwan Corporation that would operate a Taiwan Major League (TML, or Tai- 
wan Da Lianmeng) to begin play in 1997. Qiu, a major figure in the Taiwan baseball world ever since his sports network TVIS began broadcasting CPBL games in I994, gambled that one baseball league was not enough for the island.

The new TML was designed to trump the CPBL-not with better quality baseball, but with a media-savvy and authentically "Taiwanese" approach that made the old league's "Chinese" identity look like cheap outdated gimmickry. This explicitly politicized strategy would fit perfectly within the dialectic between globalization and local Taiwanese identity that drives so much of contemporary Taiwan society and culture. Pride in the unique aspects of Taiwanese culture and in the unique contributions that Taiwan can make to today's world justifies a place for Taiwan in the international community. Likewise, the pursuit of international (often specifically American or Japanese) trends and symbols can also be understood as solidifying a status for a Taiwan independent of the PRC and its threats of reunification. Mastering this dialectic between the uniquely Taiwanese and the international or universal is necessary for the success of any cultural, social, commercial, or political enterprise in contemporary Taiwan. And the Taiwan Major League was an endeavor that fit all of these categories.

Contacts with foreign baseball networks, as with the CPBL, were an important priority for the Taiwan Major League. In April and May r996, top TML officials traveled to Japan and the United States, making important top-level connections with representatives of league offices and top teams like the Orix Blue Wave, Seibu Lions, and the Atlanta Braves (Gao r997, 2). ${ }^{25}$

The Taiwan Major League worked to avoid being overwhelmed by the American influence that came to plague the CPBL so. To be sure, TML teams employed many American and Latin American players in their quest for championships, and the league made the most of its connections to American baseball, even playing "Take Me Out to the Ballgame" during the middle of the seventh inning of each TML game. Yet the league made no secret of its preference for what it calls a "Japanese way" (heshi fengge) or "Oriental wind" (dongyang feng) in recruiting Japanese coaches and players (TWRB August $x_{4}, 1998,20$, and December 30, I998, B-7). In recruiting foreign players, TML team officials admit their fondness of Japanese players, praising their skill and personal discipline that make them "more manageable" than Latin American ballplayers (HXXWW June I3, 2000). These gestures to a shared Taiwanese-Japanese past and future serve both as a marker of the TML's cosmopolitan distinctiveness and as a claim to a proud supranational Asianism for the twenty-first century (Ching 2000, 236).

Unlike the CPBL, the Taiwan Major League did not allow these productive connections with the international to overshadow the league's explicitly "Taiwanese" character. ${ }^{26}$ Where the CPBL clung to dry stereotypes of "traditional China," the TML's identity is squarely based in Taiwan's unique culture and history. The name of the Naluwan Corporation that runs the TML and the names of the four teams-Agan (Jin'gang, Robots), Fala (Leigong, Thunder Gods), Gida (Taiyang, Suns), and Luka (Yongshi, Braves)-were taken from the languages of Taiwan's aboriginal tribes that, as described above, made such great contribu- 
tions to the history of Taiwan baseball. Team uniforms were designed to reflect "the special characteristics of the aboriginal peoples," but also only after "consideration of the colors and design of professional baseball uniforms of other nations" (Naluwan Weekly r997b, 3). In case these measures did not make the Taiwan-centric flavor of the league distinctive enough, the TML chose as its r999 league slogan: "Focus on Taiwan, the local comes first" (Taiwan youxian, bentu di yi) (TWRB December 4, 1998, B-6).

Another important choice made by the Taiwan Major League was to follow what it calls a "territorial philosophy" (shudi zhuyi), in which each team has a city or region that it calls home, unlike the CPBL, whose teams never enjoyed a true "home-team advantage." 27 The TML teams play half of their games in their home city or region--the Suns in Taibel, the Robots in Taizhong, the Braves in Jiayi-Tainan, and the Thunder Gods in Gaoxiong-Pingdong. The "territorial" doctrine of shudi zhuyi dictates that teams take these "home" connections seriously. Before the I997 season, teams took part in New Year's ceremonies in their home cities and took oaths before city officials to serve as loyal and morally upright representatives of these cities. 'The Robots' team oath, taken on January 17 , 1997, before the Taizhong Municipal Assembly, went as follows:

I. We will love and cherish Taizhong, and will work together with our Taizhong neighbors to promote the baseball movement,

2. We will sink roots in Taizhong, and will join together with our Taizhong neighbors in working for the public good.

3. We will have the fervent spirit of a rainbow, and are determined to win the highest glories in this first baseball season for our Taizhong neighbors.

4. Our hearts are full of sincerity, and we will work together with our Taizhong neighbors to create a healthy baseball movement.

5. We will play conscientiously and diligently, vowing to work with our Taizhong neighbors to make this the new home of "power baseball" [qiangli bangqiu]. (Naluwan Weekly I997a, 6)

These hometown loyalties took on more significance with the tragic earthquake that struck central Taiwan in September I999. The Robots quickly dubbed themselves "The Disaster Area Team," and set up their own Robots Van that delivered disinfectants, vitamins, and medicines to the residents of the epicenter at Zhongliao Village, Nantou County (S/RB October 8, 1999, B-6).

The Jiayi-Tainan Braves took their municipal vows seriously as well, canceling one of their 1997 preseason games against the Thunder Gods so that players could attend miaohui temple festivals in Beigang, Xingang, Puzi, and Dongshi during the Lantern Festival in late February (TWRB February I2, I997, 9). That fall, during Jiayi County Magistrate Li Yajing's bid for reelection, Braves Manager Zhao Shiqiang (interestingly, a second-generation mainlander) registered as an official member of Li's campaign team. He and his coaching staff put in tireless hours drinking with, feting, and entertaining Jiayi County's many 
power brokers, as well as participating in local religious festivals (ZYSB November $8,1997, C-8)$. The Braves capturing the TML championship in early November certainly did nothing to hurt $\mathrm{Li}$, who weeks later recaptured the magistrateship by a comfortable margin.

The most spectacular demonstrations of the Taiwan Major League's distinctively "Taiwanese" character come in two of the league's trademarks. The first was its "tradition" of holding its season openers on February 28 (228) at the Jiayi Municipal Stadium. Little explanation need be given of the colossal significance of this date in Taiwan's history. Yet the TML stripped the powerful date of the anti-Nationalist/mainlander acrimony that marked private, subversive observances of the 947 massacre for almost five decades. Instead, it transformed 2.28 into a celebration of everything that is truly "Taiwanese." President Lee Teng-hui (Li Denghui) threw out the first pitch at the 1997 Opening Game, after ignoring the CPBL's repeated invitations for him to appear at their opening game, as he had in 1996 (HXXWW January 2I, I998). Leaders of Taiwan's nine official aboriginal tribes also were honored in the game's opening ceremonies. The decision to honor Jiayi with this tradition (and with the TML's marquee team, the Braves), was a very conscious one as well, as the TML paid its respects to this "baseball capital" of Taiwan.

The symbolism of the Taiwan Major League's new "228 Opening Game" tradition is powerful and complex. The TML's I997 opener showed off the league's international connections, with official representatives of the American, Japanese, and Korean major baseball leagues and even stars like Jackie Chan in attendance. But the chief emphasis of the "228 Opening Game" is clearly on the local-the "Taiwanese." Where the CPBL-perhaps constrained by the politics of the late I980s and early r9gos-presented itself as a "Chinese" baseball league, the TML did everything it could to be a truly "Taiwanese" league. Local politics, local religion, tribute to the aboriginal tribes of Taiwan, and even modern Taiwanese history's most sacred date, February 28 , were all included in the elaborate rituals of the new Taiwan Major League.

Participation in the international sport of baseball and impressive connections to powerful baseball networks all over the world created a cosmopolitan image for the TML. Yet the early success of the TML came from its bold celebration of the local, the authentic, the Taiwanese. Even though the new league offered an inferior quality of baseball than the old CPBL, the Taiwan Major League consistently outdrew its rival at the gates. One random (but telling) example was a night in September 1998, when 14,385 Jiayi fans attended a TML Braves-Robots game, compared to crowds of just 629 and $\mathrm{I}, \mathbf{I I} 3$ that showed up for CPBL games in Taibei and Gaoxiong ( $L H B$ September 23, 1998, 29).

Finally, the Taiwan Major League's official theme song, "Naluwan-True Heroes" (Naluwan-Cheng-keng e Eng-hiong) was perhaps the finest example of the fascinating mixture of historical and cultural legacies that makes Taiwan society so unique and dynamic and so difficult to fit within most standard models of historical, economic, cultural, social, or political development. The TML anthem, supposedly based on rhythms and patterns of several types of aborigi- 
nal tribal songs, ${ }^{28}$ consists of lyrics (see below) in Mandarin, Taiwanese, English, Japanese, and Aboriginal languages:

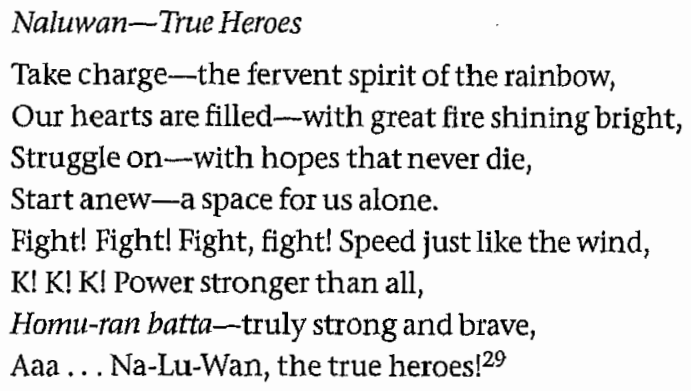

Each singing, each playing of this league anthem became a neat and tidy recreation of the last several centuries of Taiwan history and culture. To be sure, little room for critical analysis of or retrospection on this history was allowed in this rousing, commercial theme song. But the tune was one more way in which the TML sought to portray itself as the true heirs and "the true heroes" of the proud, complicated history of Taiwan.

\section{"YOU'VE GOT THE F--ING TROUBLE": THE DECLINE OF TAIWANESE PRO BASEBALL, 1997-2001}

In the winter of 1997 , the future of 'Taiwan's pro baseball enterprise looked bright. The CPBL was beginning the first year of a rich new television contract with the China Trust conglomerate worth NT $\$$ I. 5 billion (U.S. $\$ 60$ million) over three years-seventeen times more than the league's previous deal with TVIS. The new Taiwan Major League, while stirring up controversy by stealing some of the CPBL's best players, promised to provide healthy competition for the old league.

The CPBL enterprise was also newly energized by a revival in Jiayi, described earlier as the traditional home of Taiwanese baseball. Jiayi's new fourteen-thousand-seat municipal baseball stadium was completed in I997, with twenty-four CPBL games scheduled there for that summer. The new China Trust Whales, the CPBL's seventh team, chose Jiayi as their home base. This city also happened to be the hometown of Whales manager Li Laifa, another I97os Little League star who played pro ball in Japan and managed Taiwan's 1992 Olympic team.

Unfortunately, 1997 would bring only disgrace, both domestic and international, to the CPBL. In late January I997, law enforcement uncovered a gambling scandal that revolved around the fixing of CPBL games by ballplayers in return for huge payoffs-often double a player's monthly salary. The nation was shocked by the front-page news that some of the game's greatest and most popular stars had accepted payoffs of NT \$300,000-500,000 (U.S. \$II,000-I8,000) 
per game that they threw for the local gangs handling the "gambling" on each team. The China Times Eagles threw games most spectacularly; it was revealed that the entire team was bought off regularly for a single team fee of NT \$7.5 million (U.S. $\$ 270,000$ ) per game (TWRB February 2, I997, r). ${ }^{30}$

This scandal, later found to be linked to gambling interests in Hong Kong and Macao as well as southern Taiwan, nearly led to the unraveling of the league as the baseball public learned the sordid details of this enterprise. And, unfortunately for the home of Taiwanese baseball, the scandal was centered in the city of Jiayi. Three Eagles players from Jiayi ${ }^{31}$-all members of the 1992 Olympic team-were at the core of that team's game-fixing plans with the powerful Xiaos of Jiayi, a crime gang whose three brother/leaders also embellished their illicit might by occupying top posts in local government. ${ }^{32}$ Jiayi native Jiang Taiquan, I992 Olympic team captain and a Lions star outfielder who was to join the Whales for their inaugural season, was also indicted for fixing games for the hometown Xiao Gang. ${ }^{33}$ This was a tricky business: Jiang and Lions star pitcher Guo Jinxing lost some NT \$200 million (U.S. \$7.3 million) of the Xiaos' money in one game (Lions vs. Bulls, August 28, 1996) by "accidentally" winning after assuring gamblers that the Lions would lose (TWRB February 14, 1997, 3, 9; LHB February $14,1997,3)$. The powerful Xiaos were not men to suffer gambling losses like this gladly. Another Lions outfielder and Jiayi native may have learned this lesson the hard way; Wu Linlian went missing without a trace after he became a target of investigation in the scandal in February I997 (TWRB February $12,1997,9$ ).

No team or player was safe from these gangs and their members' frustrations when their favorite teams won. Loyal Elephant gamblers furious at their team's winning ways kidnapped five Elephant players, pistol-whipping one and shoving a gun down the throat of another. Seven Tigers players (including two Americans and two Puerto Ricans) were abducted at the Gaoxiong Stardust Hotel by gun-packing thugs who used similarly violent ways of requesting the players to throw games (TWRB August 7, I997, 5). And one day while picking his daughter up at school, Dragon manager Xu Shengming was stabbed in the lower back by a representative of yet another gambling outfit. ${ }^{34}$

Understandably, fewer and fewer fans decided to pay much attention to a league whose games they feared were still being decided by sleazy mob kings. Attendance fell by 55 percent for 1997 , a change also due to the easier availability of American and Japanese baseball games via Taiwan's booming cable TV market. Over the next two years, the CPBL tried to find new ways of appealing to Taiwan's increasingly inattentive public. Yet nothing-new slogans for the league, such as "Continuing our traditions and looking to the future" and "Exciting and good baseball, extremely lively" (TWRB February 6, I999, B-8), promotional events with movie star Kevin Costner and Vice President Lian Zhan ( $H X X W W$ January 20, I998; ZYSB February 6, 1998, C-6), or even plans for the Sinon Bulls and Weichuan Dragons to play China's national team in Xiamen (TWRB July 3I, 1998, 20; ZYSB August I, I998, C-8)-was enough to convince 
Taiwan's baseball public of the league's continuing relevance. By the I999 season, fan attendance for most games was below a thousand. One day in October 1999, the two scheduled CPBL games, both crucial to the late-season pennant race, drew just $I 76$ and $x 16$ fans respectively (SIRB October 8, 1999, B-6). During the winter after the 1999 season, the league lost two more teams, as the Mercuries Tigers and three-time defending champions Weichuan Dragons both cited financial pressures in folding their baseball operations. ${ }^{35}$

This sad series of events came at the exact moment when American and Japanese major-league teams were beginning to aggressively scout young Taiwanese baseball talent. In 1999-2000, seven young players who would have starred in Taiwan signed lucrative contracts with American and Japanese teams. The Los Angeles Dodgers, well connected in Taiwan, struck first by signing young outfieider Chin-Feng Chen. Chen was named League MVP (Most Valıable Player) in his first U.S. minor-league season (California League, Class A) in I999, and at age twenty-four he made his celebrated major-league debut in September 2002. ${ }^{36}$ The Colorado Rockies were next, bagging eighteen-year-old Tsao Chin-hui (Cao Jinhui), toast of the I999 World Junior Championships, with a U.S. \$2.2 million contract in 2000 . Tsao, who had been scouted by majorleague teams since junior high school, has since been called "the Hope Diamond of the Rockies' minor league system" (Renck 20or). The New York Yankees, Seibu Lions, and Chunichi Dragons also invested heavily in young Taiwanese players whose talent the CPBL and TML-already crippled by the events described-now had to live without.

A final humiliation came in March 200I, on the opening night of the TML's fifth season of play. The Taiwan Major League, although not tainted directly by the CPBL's gambling problems, had also seen the popularity of its inferior quality of baseball wane since 1997 . By 200I, the two rival leagues, both plagued by several consecutive money-losing seasons, were seriously considering a merger and a further downsizing of the baseball enterprise. The TML shortened team schedules from eighty-four to just sixty games each and desperately tried to attract fans with a new marketing gimmick-naming four pop stars as official "spokespeople" for each of the league's teams. Rapper Zhang Zhenyu, spokesman of the Gaoxiong-Pingdong Thunder Gods, was scheduled to kick off the festivities at Chengqing Lake Stadium, along with ROC Legislative Yuan Speaker Wang Jinping (also TML chairman) and Ronald McDonald. The game itself was to be a milestone in TML history, marking the debut of Taibei Suns Manager Li Juming, the former Little League and Brother Elephant star idolized as Taiwan's "Mr. Baseball." The season got off to an unbecoming start, however, when Zhang enthusiastically performed his song "Trouble," repeatedly screaming in English before the sellout crowd and a national TV audience, "You've got the f---ing trouble! You've got the f---ing trouble!" (CP April I, 20or). Zhang's league handlers, not to mention Ronald McDonald, were surely humiliated by this display of bad judgment, but his words were also a very accurate diagnosis of the state of Taiwanese pro baseball at the beginning of the twenty-first century. 


\section{CONCLUSION}

On December 31, 2000, Taiwan's President Chen Shui-bian made his first New Year's address to the nation, remarks meant to sum up his first seven months in office and also to "Bridge the New Century." Chen had much to discuss, from the political revolution completed by his own victory and his once-illegal party's climb to power, to the world economic recession and entry into the World Trade Organization, to Taiwan's tense relations with China and the increasing possibility of an armed conflict across the straits. The president summed up his remarks with comments on the unique "Taiwan spirit" forged during the twentieth century and closed his address with an interesting symbol of the Taiwan experience:

I recently had the opportunity to read some of Taiwan's historical records and was deeply inspired by one picture in particular: a portrait of the Maple Leaf Little League baseball team. In this black-and-white photograph, there was a barefoot aboriginal boy at bat. His face showed full concentration, as he focused all of his energy on his responsibility. Meanwhile, his teammates stood by on the sidelines anxiously watching and giving encouragement. Such a beautiful moment perfectly captures twentieth-century Taiwan and is a memory that I will never forget.

My dear fellow countrymen, history has passed the bat to us, and it is now our turn to stand at the plate. The twenty-first century will undoubtedly throw us several good pitches, as well as one or two dusters [huaiqiu]. Regardless of what is thrown to us, however, we must stand firm and concentrate all of our strength and willpower for our best swing. (Chen 2000; Chen zooI, 3)

Again, it is no accident that Chen chose this Maple Leaf image to encapsulate Taiwan's history and identity (although he may be understating the case by calling a possible Chinese invasion of Taiwan a mere "duster"). I have tried to theorize here that a history of Taiwanese baseball is an appropriate and crucial window for understanding the complicated histories and cultures of modern Taiwan. Starting with the game's Japanese origins, followed by the high-profile successes of Taiwanese Little League baseball from the I960s to the I 980 , baseball was an important avenue by which Taiwanese people have navigated the historical relationships with the Japanese, the Chinese Nationalists, and their American allies. Now, at the turn of the century, as the search for a uniquely Taiwanese identity is given official sanction, baseball is a crucial element of this identity. ${ }^{37}$

Despite the depths to which the professional game's popularity has sunk, recent events still demonstrate the centrality of baseball in Taiwan. Taiwan successfully hosted the 200 International Baseball Association amateur championships, a development that speaks to the weight that Taiwan carries in the world baseball community despite efforts by the PRC to shut down this type of 
international Taiwan presence. Many rejoiced when, in early 2003 , it was announced that the rival CPBL and TML would end their six-year rivalry and merge into a single six-team league. Taiwan's baseball heritage has the attention of the art world. Taiwan's I 999 Golden Horse Award for Best Documentary went to director Xiao Juzhen's "Maple Leaf Legend" (Hongye Chuanqi), a film about the men who made baseball history for Maple Leaf Elementary School, Hongye Village, Taidong County, and all of Taiwan so many decades ago.

More than one century ago, Mark Twain wrote that baseball was the perfect expression of the American society of his day, declaring that the game had become "the outward and visible expression of the drive and push and rush and struggle of the raging, tearing, booming nineteenth century!" (Guttmann 1994, 79). Robert Whiting and William Kelly have both seen Japanese baseball as the perfect symbol of different elements of that nation's modern history and culture. ${ }^{38}$

The same can be said for Taiwan. Baseball's position at the center of a new Taiwanese nationalism and project of self-definition is illustrated perfectly by the NT \$50o bill issued in December 2000 . As the sage visage of the iron-fisted Generalissimo Chiang Kai-shek is removed from Taiwan's currency for the new millennium, what better indigenous symbol to replace him than an image of the young Little Leaguers who won his regime so much fame in the ro7os? Now, instead of facing the gaze of the Chinese military leader forced on Taiwanese youth for four decades as "Savior of the People," Taiwan consumers handing over NT $\$ 500$ are inspired by the smiles on the faces of the Puyuma aborigine boys from Taidong County whose Pacific Cup victory celebration is portrayed on the bill ( $L H B$ December $16,2000,6)$. At the turn of the twenty-first century, these are the healthy and "authentic" faces that Taiwanese people today take to represent their island nation and-as they have for nearly a century-express through their national sport of baseball. 
4. This term represents quasl-family ties between upline and downine. During my fieldwork, people often asked me, "Whose babe are you?" This means, "Who is your upline?" Although it secms intimate, the term "babe" in Mandarin is rarely used, especially among nonfamily members. This usage somewhat contradicts the conservative feature of Chinese vocabulary and culture in relational expression. It is also part of the reason why outsiders often regard Amway members to be affectatious.

5. Pseudonyms have been used here and throughout to ensure informants' anonymity.

6. In the direct selling industry, "OIP" is the abbreviation of "opportunity." Direct selling companies hold regular meetings to explain their company histories, reward systems, and products and to introduce the opportunity represented by the direct selling business.

7. Members who have the same original uplines establish a quasi-familial bond. They are highly involved with each other in this small group and participate in formal and informal meetings together.

8. Amway members-especially if they are students or have not yet earned any titledo not usually initiate conversations about direct selling in the work setting. Many hesitate to reveal their distributor status at work, fearing that coworkers may think of them as "money slaves," ruining their reputation and relations with their colleagues. Therefore, distributors usually practice direct selling implicitly at work. For instance, they might "casually" use Amway cosmetics or muitivitamins in front of coworkers and begin to talk about Amway only when colleagues show interest or curiosity about the products.

9. This concept from Foucault (Martin et al. 1988) refers to the means with which the self, medical techniques, or social forces are used to transform the body.

Io. Amway people call all occupations except direct selling "traditional jobs" because these jobs cannot offer people what direct selling can: wealth and freedom at the same time.

II. This report provided an overall review of the distribution of direct salespeople, whereas the statistics of any single company were not available. The Amway Company refused to release any statistical data regarding its distributors' information, so I was not able to show the pyramidal distribution of Amway members in this chapter.

\section{CHAPTER 9. BASEBALL, HISTORY, THE LOCAL AND THE CLOBAL IN TAIWAN}

Author's note: Previous versions of this essay were presented at the North America Taiwan Studies Conference, University of Texas at Austin, May 29-31, I998, the Western Conference of the Association for Asian Studies Annual Meeting, Long Beach, October 6-7, 2000, and the Fifth Annual RGTHC Conference on the History and Culture of Taiwan, Los Angeles, October I2-I5, 2000. I hereby thank the participants of these conferences, as well as Chunwei Yu and Jeffrey Wilson, for their helpful comments.

I. Emphasizing his official commitment to baseball, Chen invited members of the Jiayi-Tainan Braves of the Taiwan Major League to perform a skit about Taiwan's 1969 Little League world championship team at his inaugural celebration ( $H X X W W$ May 21. 2000).

2. Exceptions to this universal adherence could only really come in ideological attacks on modern sport or on modern capitalist society altogether. In I952, American feathers were ruffled when the Soviet magazine Smena published a piece on American baseball, calling it "beastly battle, a bloody fight with mayhem and murder," a harsh capitalist venture that discarded players "with ruined health and also often crippled ... [to] increase the army of the American unemployed." The game, according to Smena, was merely a typically awful American perversion of the Russian game lapta, which had been "played in Russian villages when the United States was not even marked on the maps" (NYT September 16, I952, I, and September $\mathrm{I} 7, \mathrm{I} 952,30$ ).

3. Baseball was not played in Taiwan under Qing rule, although Chinese studying in the United States were playing baseball as early as 1873 
4. One roster (Zheng 1993, r15) lists aborigine shortstop Chen Gengyuan under his Japanese name, Agarimatsu Kōichi,

5. The Kōshien tournament, founded in $\mathrm{I}_{9} \mathrm{I}_{5}$, began inviting Taiwan representatives in 1923 . From 1923 to I930, all the Taiwan teams that qualified for Kōshien were Japanese teams from Taihoku (Taibei) (Gao I994, 54-55).

6. Kanō won their first three games by the combined score of $32-9$ before finally losing in the championship game (Zheng 1993, 124).

7. Wu led the Japanese League in batting in I942 and I943, was named League MVP in I943, pitched a no-hitter in I946, and retired with a .272 batting average over twenty seasons (Zheng I993, I2I). There were Taiwan aborigine standouts in the Japanese leagues as well. Luo Daohou of the famed Hualian Ami tribal baseball teams played for the Tokyo Senators from 1936 to I938, and Ye Tiansong, another Ami, starred for the Nankai Hawks from I940 to I949 (Gao I994, 99-IOI).

8. This was not a uniquely Taiwanese strategy by any means; elsewhere in the Japanese Empire, the Korean nationalist martyr Yŏ Un-hyŏng sponsored athletics in the I93os as a similarly indirect mode of resistance to the forces of the colonial power (Deane 1999, 48),

9. Provincial Chief Administrator Chen Yi served as meet chairman.

ro. Foreign teams were not even allowed to compete at Williamsport in 1975 , so the Taiwanese boys won ten titles in twelve years of competition.

Ir. Months after these victories, the Maple Leaf Elementary School principal, coach, and head administrator were all sentenced to a year's imprisonment by the Taidong County Local Court for these gross violations (Wang 1994, 79).

12. And to boot, the Chinese on the banner was written in mainland-style simplified characters that were illegal to use in Taiwan!

r3. This shot drew harsh protests from the ROC government, which asked ABC to avoid pointing their cameras at Chinese-language messages that could possibly be subversive.

I4. Many baseball players of aboriginal backgrounds thrived in Taiwanese professional baseball in the I990s. But old stereotypes die hard, and no matter how much glory these players have won for Taiwan, they are still treated differentiy from Han Taiwanese. A recent example is the Taibei Suns Fan Club's coordinated chants of "Savage [hoan-a] get out!" directed at Jiayi-Tainan Braves pitcher Chen Yixin during the I997 Taiwan Major League Championship Series (ZYSB November 3, I997, C-8).

15. For example, the Chuiyang Elementary School team, always a force in their home city of Jiayi, wore caps emblazoned with an interlocked "CY" that was a dead ringer for the Tokyo Yomiuri Giants' trademark "YG" design (Su 1996, 64).

I6. In fact, the Nationalist government could even use baseball as a mode of anticommunist propaganda. In I987, an official article told of how several mainiand fishermen taking refuge from a typhoon in the port of Taoyuan were absolutely stymied by the experience of watching "Free China [i.e., ROC] sluggers pound Japan 9-3 in a live telecast of the I4th Asian Amateur Baseball Championships from Tokyo... The most difficult thing was convincing the mainland fishermen that the game they were watching their ROC compatriots play in Japan was actually taking place at that very time and being beamed by satellite to Taiwan" (Free China Journal I 987,3 ).

17. Tellingly, the ROC Professional Baseball Preparatory Committee stated that one reason for launching the CPBL was to "[stem] the import of Taiwan's best players by Japanese teams" (Free China Journal I988, 2).

I8. These four corporations had sponsored semipro teams in Taiwan before 1990.

19. Of the nineteen foreigners who played during the CPBL's first season, only two had major-league experience: Tiger infielder Jose Moreno (I980 NY Mets, $198 \mathrm{I}$ San Diego Padres, 1982 California Angels) and Elephant pitcher Jose Roman (1984-1986 Cleveland Indians).

20. The Chunichi minor leaguers were joined by the big-league Dragons' two Taiwanese stars, Guo Yuanzhi and Chen Dafeng. 
2r. After thirty-eight CPBL games that year, foreign pitchers had won thirty-five decisions and thrown 8x percent of the innings (ZYSB March 25, 1998, C-8).

22. Of the second-place Sinon Bulls' eleven pitchers, nine were foreign. The foreign pitchers' combined record was $57^{-45^{-2}}$ that year; the two Taiwanese pitchers were I-O-O.

23. An indication of foreign dominance of the CPBL in $1997 \mathrm{can}$ be seen in the season statistical leaders. In the major categories given, there were the following number of foreign players in the top ten: batting average: eight; home runs: eight; runs batted in: seven; victories: seven; and earned run average: six.

24. A week later, O'Malley attended the CPBL's Opening Night in Tainan and addressed the crowd, calling the game "the I997 Opening Game for professional baseball the world over" (TWRB February $24,1997,9$ ).

25. A deal made with the International Division of America's Major League Baseball (MLB) has sent distinguished coaches like Bill Plummer, Greg Riddoch, Fernando Arroyo, and Jim Lefevbre to serve as officiai MLB advisors to the league's teams. The Taiwan Major League sent all eight of its umpires to the MLB-approved Brinkman-Froemming Umpire School in Florida for a thirty-one-day training session (TWRB February 5, 1997, 9).

26. In I997, 42.7 percent of the TML's players came from abroad. But the TML wisely lowered this limit to seven yangilang per team for 1998 , which reduced the ratio of foreign players on TML rosters to less than 30 percent (ZYSB October 13, I997, C-8).

27. This concept is very possibly based on the Japanese professional soccer J-League's official "Mission" of community sport.

28 . The official recording of the anthem, performed by seven aboriginal singers, was made into a baseball music video and also sold in stores on an official Taiwan Major League CD (Naluwan Weekly I997C, 5).

29. The first four lines of the anthem are in Mandarin, the fifth in Taiwanese, the sixth in English and Taiwanese, the seventh in Japanese and Taiwanese, the eighth in "Aborigine" and Taiwanese (Huang I997, 5).

30. Dubbed the "Black Eagles" (Heiying), the team was suspended from the league in late 1997 and formally disbanded in 1998 (ZYSB November I7, 1997, C-8; ZGSB September I6, 1998, 3I).

31. They were Zhuo Kunyuan, Cai Minghong, and Zhang Zhengxian. Cai and Zhang were alsc members of the Puzi Tornados team that won the 1979 Little League World Series.

32. They served as Jiayi City assembly speaker, Jiayi City agricultural cooperative manager, and Jiayi County assembly speaker (LHB February $\mathrm{I} 4, \mathrm{I} 997,3$ ).

33. After being banned from Taiwan professional baseball, Jiang got a second chance five years later in mainland China as coach of the Tianjin Lions of the new China Baseball League and manager of the PRC national team. The Tianjin team, which evidently has a poor vetting process, also hired fallen Taiwan stars Guo Jiancheng and Zheng Baishengalso banned in 1997 for throwing CPBL games-as coaches (TTO May 9, 2002).

34. Although no one admitted it at the time, these underworld connections and violence associated with the CPBL were a main factor in the defection of so many of the league's stars to the new Taiwan Major League before the 1997 season. One player who attempted to make the jump but was also found to have thrown games in the CPBL was Lion pitcher Guo Jinxing, the finest pitcher in Taiwan during the mid-I99os. He was banned from playing in either league--but soon made headlines another way, when he was arrested in I999 for using a knife to hold up a woman at an ATM (ZYSB June 29, 1999, 6).

35. If nothing else, the downsizing to four CPBL teams has solved the problem of foreign players' dominance of the league. Whereas there were too few good Taiwanese players to fill seven CPBL team rosters, which prompted the need for so many yangiang, there are enough to fill four. As of the 2000 season, CPBL teams carried only two foreign players at a time.

36. At Chen's debut at Dodger Stadium, a celebratory message from Taiwan President Chen Shui-bian was shown on the big-screen scoreboard before the game. Nike also 
planned for a December 2002 release of Chen's own signature baseball cleats, "Air Zoom Respect SP" (TTO September I3, 2002).

37. A recent example is President Chen Shui-bian's public statement that Taiwanese culture should not be a marginalized segment of Chinese culture, calling it instead a substantial and unique civilization of its own (TTO August 5,2000 ).

38. Where Whiting has privileged essential "Japanese" or "samurai" qualities stich as "unity and team spirit," Kelly concentrates on the postwar invention of racially pure or authoritarian categories that were part and parcel of the r960s-1970s Japanese rise to economic dominance (Whiting 1989; Kelly I998, 102-108).

\section{CHAPTER 10. YANG-SUCKINC SHE-DEMONS}

Author's note: This is a revised version of a presentation I gave at the 200 Association of Asian Studies Conference under the same title. I am grateful for the insightful responses of the audience members at that time.

I. The full title of the movie is A Chinese Ghost Story (Qian nü you hun), but for brevity's sake I will refer to it simply as Ghost Story.

2. Indeed, to say "Fong Kong cinema" is something of a misnomer in that it is heavily influenced by Taiwanese capital investment and creates films with an eye to pleasing Taiwanese and mainland audiences (Lo 200I, 26I). Since the early r980s, Hong Kong films have become a dominant force in Taiwan's cinemas, and Taiwanese investment and influence on the film industry has increased accordingly. Hong Kong cinema can thus be seen to be transnational cinema and reflects Taiwanese concerns as much as those of people living in Hong Kong.

3. Joey Wong (Wang Zuxian).

4. For more on the historical images of Chinese prostitutes as manipulative and scheming, see Hershatter (1994, I997).

5. Historically in mainland China and until the last few decades in Taiwan, it was common for families to adopt young girls and raise them with the intent of marrying them to their sons (A. Wolf 1976 , I980, I995; M. Wolf 1968, I972). Thus, even this unexpected twist was a culturally valid option at that time.

6. People who die before they are wed are structurally anomalous. 'To remedy this situation, "ghost marriages" take place in which a living person will marry a ghost and take on the responsibility for providing religious offerings to that ghost. For more on ghost marriages, see Jordan 1972. 423).

7. It is surprisingly common for ghosts to bear living children in such tales (Yu 1987 ,

8. A Chinese Ghost Story 3 (Dao dao dao: Qian nü youhun 3). The first sequel, A Chinese Ghost Story 2 (Renjian dao: Qian nü youhun 2 ), has many of the same actors and actresses. In Ghost Story 2, however, the heroine is not presented as a ghost, so I will not address the film here.

9. Later she confesses that other men who took the money had their hearts or livers torn out $(\mathrm{PuI} \mathrm{I} 766,50)$.

ro. The link between castration anxiety and fox spirit's depletion of male essence is reinforced by the culture-bound syndrome of koro, in which men become convinced that their penises are shrinking away. Victims of koro, it has been reported, often state that the cause of their maladies is fox spirits who are believed to "collect" men's penises to transform to human form (Prince 1992, I23, I28-I29; Tseng et al. I988, I,539), to cause penile shrinkage by "pulling at the other end" (Cheng 1997,62 ), or more generally by collecting male energy (yang essence) to gain immortality (Prince 1992, 128; Cheng 1996, 76).

Ir. See Ahern I975, I93, 202 and I988, 165; Andors I983, 50; Gates I996, I85-I87; Harrell I986, II3-II4; Hsu I948, 209; Moskowitz 200I; Seaman I98I, 395 and I98I, 388-389; A. Wolf 1974 , I5I; and M. Wolf I974, I60. 